\title{
Construction of National Standardization System for Juvenile Products in China
}

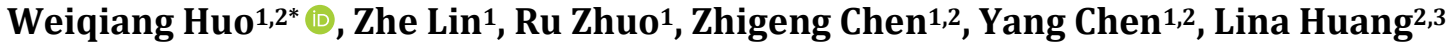 \\ ${ }^{1}$ Guangzhou Customs District Technology Center, Guangzhou, China \\ ${ }^{2}$ Standardization Working Group on Juvenile Products of Standardization Administration of China, Beijing, China \\ ${ }^{3}$ Shenzhen Technology University, Shenzhen, China \\ Email: *huowq@iqtc.cn
}

How to cite this paper: Huo, W. Q., Lin, Z., Zhuo, R., Chen, Z. G., Chen, Y., \& Huang, L. (2021). Construction of National Standardization System for Juvenile Products in China. American Journal of Industrial and Business Management, 11, 341-351.

https://doi.org/10.4236/ajibm.2021.114022

Received: March 12, 2021

Accepted: April 11, 2021

Published: April 14, 2021

Copyright (c) 2021 by author(s) and Scientific Research Publishing Inc. This work is licensed under the Creative Commons Attribution International License (CC BY 4.0).

http://creativecommons.org/licenses/by/4.0/

\begin{abstract}
China is the world's largest manufacturer and exporter of juvenile products, while the standardization system for juvenile products still needs to be perfected and still has a certain gap with foreign advanced systems. To promote the standardization of juvenile products in China and solve the limitations of the existing standards system, the "Standardization Working Group on Juvenile Products" was established in May 2020 with the approval of the Standardization Administration of China. The development trend of juvenile products industry in China was analyzed in this paper, teases out the existing problems in the development of standardization, and establishes the National standardization system for juvenile products according to the working scope of the "Standardization Working Group on Juvenile Products".
\end{abstract}

\section{Keywords}

Juvenile Products, Standardization System, National Standards

\section{Introduction}

China is the largest country in the production, trade and consumption of juvenile products in the world. According to industry statistics, in recent years, the annual output value of China's main juvenile products has exceeded 650 billion yuan and the products are sold to over 200 countries and regions. The annual export value of juvenile products has exceeded 50 billion US dollars, ranking first in the world (Liang, 2020). With the social and economic development and the improvement of consumer demands, there are increasing requirements for the varieties, functions, quality and safety of juvenile products.

However, China's juvenile products are mainly low and medium-end prod- 
ucts, some enterprises have weak awareness of quality standardization and the product quality is uneven, quality problems occurred from time to time. Taking the recall data of China's consumer products as an example, in 2019, China's consumer products were recalled a total of 434 times, including 193 recalls of juvenile products, involving 2,728,100 million products (see Figure 1), accounting for over 40\% (China State Administration for Maket Regulation, 2019). The quality safety situation of juvenile products is not promising in China and there is a great demand for product standardization. This paper will seek to identify problems in domestic standardization construction, learn from the experience of advanced foreign standard systems and establish a more comprehensive national standardization system of juvenile products according to the working scope of "Standardization Working Group on Juvenile Products" (hereafter referred to as SWG 18).

\section{Development of the Standardization of Juvenile Products in China}

For a long time, the Standardization Administration of China (hereinafter referred to as SAC) has actively promoted the standardization construction of infants and children's products. At present, more than 120 national standards related to juvenile products have been developed and issued, including 31 compulsory standards (see Table 1), covering the fields of safety seats, textiles and garments, furniture, baby carriages, drinking appliances, student products, etc. in a relatively comprehensive way. A lot of work has been done in China, but there are still some limitations in the aspects of systematization, coordination and consistency. The relevant technical committees often develop standards from their respective professional fields, so that an effective liaison and coordination mechanism is lacking, which easily leads to the disharmony of cross-industry common generic technology contents in the standards. To resolve this problem, the working group on children's products in 2013 was established by SAC, promoted the comparison and analysis of domestic and international standards and

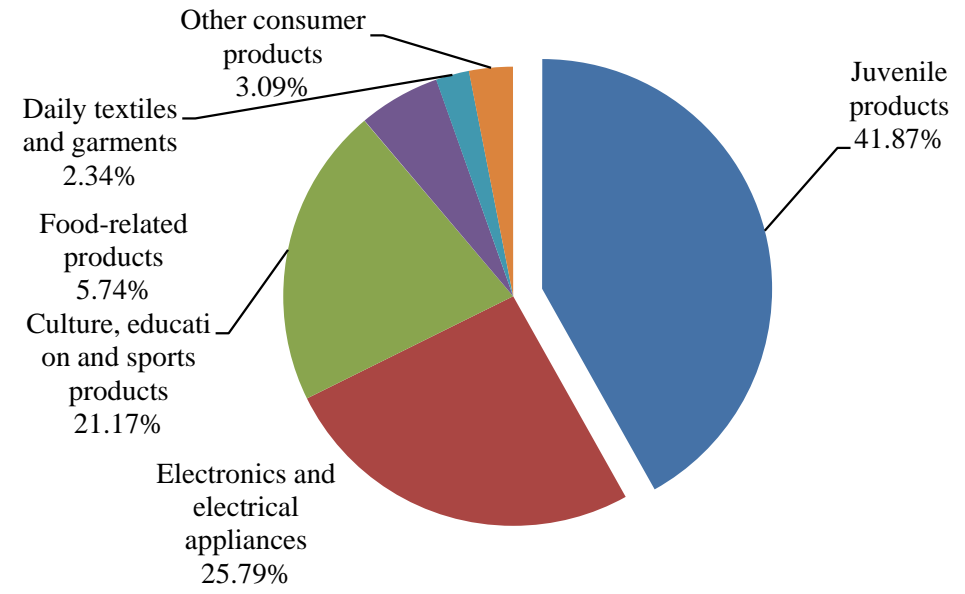

Figure 1. Category distribution of China's recalled consumer products in 2019. 
Table 1. List of compulsory standard of juvenile products in China (Standardization Administration of China, 2021).

\begin{tabular}{|c|c|c|}
\hline No. & Standard Number & title of standard \\
\hline 1 & GB 14746-2006 & Safety requirements for bicycles for young children \\
\hline 2 & GB 14747-2016 & Safety requirements for child tricycles \\
\hline 3 & GB 14748-2006 & Safety requirements for wheeled child conveyances \\
\hline 4 & GB 14749-2006 & Safety requirements for baby walking frames \\
\hline 5 & GB 28482-2012 & Safety requirements of soothers for babies and young children \\
\hline 6 & GB 29281-2012 & Safety requirements for playpens and similar cribs \\
\hline 7 & GB 30004-2013 & The safety requirements of cradles \\
\hline 8 & GB $18401-2010$ & National general safety technical code for textile products \\
\hline 9 & GB 31701-2015 & The safety technical code for infants and children textile products \\
\hline 10 & GB 25036-2010 & Children's canvas rubber footwear (shoes) \\
\hline 11 & GB 28007-2011 & Children's furniture-General technical requirements \\
\hline 12 & GB 22793.1-2008 & Furniture-Children's high chair-Part 1: Safety requirements \\
\hline 13 & GB 27887-2011 & Restraining devices for child occupants of power-driven vehicles \\
\hline 14 & GB 24406-2012 & $\begin{array}{l}\text { The strength of student seat systems and their anchorages of special } \\
\text { school bus }\end{array}$ \\
\hline 15 & GB 14166-2013 & $\begin{array}{l}\text { Safety-belts, restraint systems, child restraint systems and ISOFIX child } \\
\text { restraint systems for occupants of power-driven vehicles }\end{array}$ \\
\hline 16 & GB 36246-2018 & Sports areas with synthetic surfaces for primary and middle schools \\
\hline 17 & GB 21027-2020 & Request in common use of security for student's articles \\
\hline 18 & GB 30002-2013 & Child's toothbrushes \\
\hline 19 & GB 28477-2012 & Safety technical requirements for children umbrella \\
\hline 20 & GB 7000.4-2007 & Safety requirements for floodlights \\
\hline 21 & GB 19865-2005 & Electric toys-Safety \\
\hline 22 & GB 24613-2009 & Limit of harmful substances of coatings for toys \\
\hline 23 & GB 26387-2011 & Safety of toys-Experimental sets for chemistry and related activities \\
\hline 24 & GB $6675.1-2014$ & Toys safety-Part 1: Basic code \\
\hline 25 & GB 6675.11-2014 & $\begin{array}{l}\text { Safety of toys-Part 11: Swings, slides and similar activity toys for indoor } \\
\text { and outdoor family domestic use }\end{array}$ \\
\hline 26 & GB 6675.12-2014 & Safety of toys - Part 12 : Toy scooter \\
\hline 27 & GB 6675.13-2014 & Safety of toys-Part 13: Chemical toys (sets) other than experimental sets \\
\hline 28 & GB 6675.14-2014 & Safety of toys-Part 14: Requirements and test methods of finger paints \\
\hline 29 & GB $6675.2-2014$ & Safety of toys—Part 2: Mechanical and physical properties \\
\hline 30 & GB 6675.3-2014 & Safety of toys-Part 3: Flammability \\
\hline 31 & GB 6675.4-2014 & Safety of toys-Part 4: Migration of certain elements \\
\hline
\end{tabular}

unified the limited requirements of phthalates in juvenile products. However, in practice, it reflected that this coordination mechanism has obvious characteris- 
tics of administrative dependence, so that it was not suitable to be a regular and long-term standardization mechanism.

On May 26, 2020, the SWG 18 was established with the approval of SAC to solve the problem above (Standardization Administration of China, 2020). The Secretariat of SWG 18 is jointly hosted by Guangzhou Customs District Technology Center and Beijing Certification Center of Light Industry Council, mainly responsible for the national standards development on the general and common safety specifications for seating and carrying products, early learning products, Feeding, drinking, sucking and care products, protection products, products for supporting maternal and infant facilities in public places. SWG 18 serves as the main platform for China to develop standards on juvenile products and implement the standardization strategies of juvenile products in the future.

\section{Progress in Advanced International Standardization of Juvenile Products}

A mature standardization system for juvenile products has been established in the European Union, the United States and other developed countries and regions. Guaranteeing children's safety is taken as the primary objective in advanced foreign systems and standards are developed mainly around basic general requirements, product standards, test methods, etc., which have important reference significance for China.

\subsection{European Union}

The European Standardization of juvenile products is mainly undertaken by the Technical Committee "Child care articles" (CEN/TC 252). The standardization committee has 7 working groups mainly on general product requirements and specific product requirements. At present, 31 European standards have been issued, most of which are original standards based on the research on behavior and habits of infants and children, physiological characteristics and product characteristics. Solid basic research is an important reason why the EU goes ahead of the world in the standardization construction of juvenile products.

\subsection{The United States}

The standards of juvenile products in the United States are mainly under the charge of the 15 sub-committees on juvenile products under the Technical Committees F15 "Consumer Products" of the American Society of Testing and Materials (ASTM). At present, 35 standards have been issued. The standards mainly cover general juvenile products, wheeled carrying and cot products, swimming equipment, sitting assistance, feeding, clothing and other products. Among them, Consumer Product Safety Commission (CPSC, 2021) and ASTM developed voluntary product standards together and have taken some voluntary standards as standards cited in regulations to achieve factual enforcement to support the supervision of the quality safety of juvenile products. 


\subsection{International Organization for Standardization (ISO)}

ISO established the Technical Committee "Child Care Article" of Standardization (hereinafter referred to as ISO/TC 310) in mid-December 2020, which was upgraded and formed from the ISO/PC 310 "Wheeled child conveyances." The Secretariat is hosted by the Association Francaise de Normalisation (AFNOR). The working scope of ISO/TC 310 covers wheeled conveyances, riding and body care, protection and baby carriers, feeding and drinking appliances. The establishment of ISO/TC 310 will have an important impact on the global standardization pattern of juvenile products.

\section{Construction of National Standardization System for Juvenile Products}

With full reference to the standard systems of advanced regions and organizations such as the European Union, the United States and ISO, considering the current development of China's juvenile products industry and standards and clearly defining the responsibilities of the relevant standardization committees, the framework of the national standardization system of infants and children's products is developed around the national standard formulating and revising scope of SWG18 (see Figure 2). The system is mainly divided into four standard sub-systems: basic specifications and guides, general technical requirements, specific technical requirements of products and test methods.

\subsection{Basic Specifications and Guides}

This part is the basis for the development of juvenile products standards, which aims to provide technical support and theoretical basis for other standards of this system. Other relevant standardization committees can also refer to the

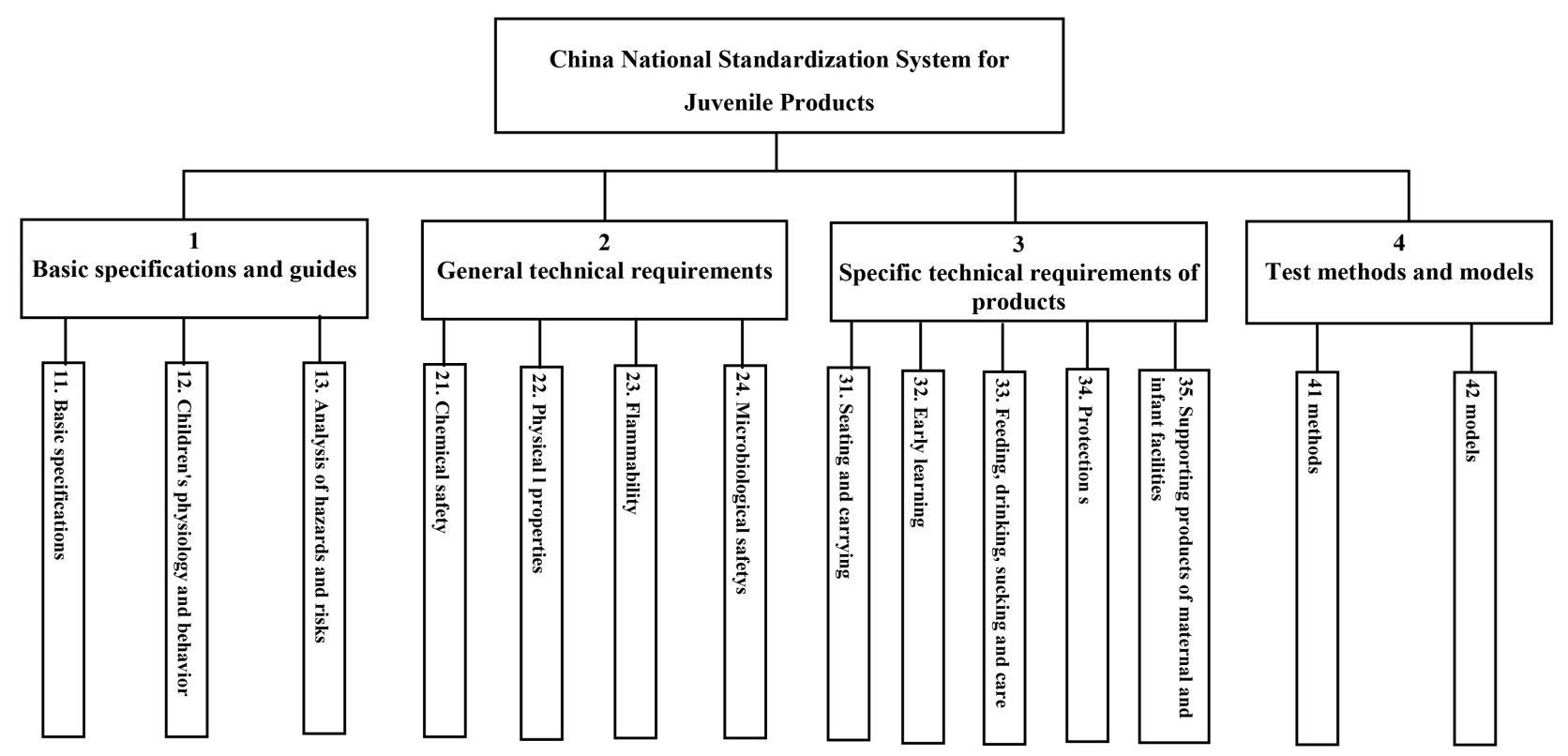

Figure 2. Technical body of national standardization system for juvenile products. 
standard research results of this sub-system as the technical guide for the preparation of relevant standards. The sub-system consists of four research areas: "Basic specifications”, “Children's physiology and behavior”, “Technical guides for safety risks" (see Figure 3).

\subsubsection{Basic Specifications and Guides}

This part focuses on defining the characteristics of juvenile products (such as use and applicable age of products). Juvenile products stretch across many professional fields, with fuzzy boundaries. In China, juvenile products are more prescriptively defined, lacking essential definition and classification principles, so it is difficult to make a clear qualitative description of juvenile products.

\subsubsection{Children's Physiology and Behavior}

The research on children physiology, behavior and habits provides an important theoretical basis for the development of juvenile product indicators in China. This part draws lessons from the experience of European Union CEN: behind each safety index of toys as well as juvenile products, are long-term tracking researches on children's toxicology, behavior, physiological development characteristics and injury cases, for example, more stringent restrictions on 19 specific migratory heavy metal elements are put forward in the new EU Toy Safety Directive (2009/48/EC), based on the Chemical in toys issued by the National Institute for Public Health and the Environment (Jgm et al., 2009).

This part focuses on the collection, analysis and research of basic data of children's physical development, physiological characteristics, behavior and habits, etc. as a basis for the development of relevant national standards. On the one hand, the research above provides important theoretical and basic data support for the follow-up safety requirements of infants and children's products; on the other hand, it also provides professional guidance for relevant standardization committees in standard formulation and revision, further reducing the dependence on foreign standards.

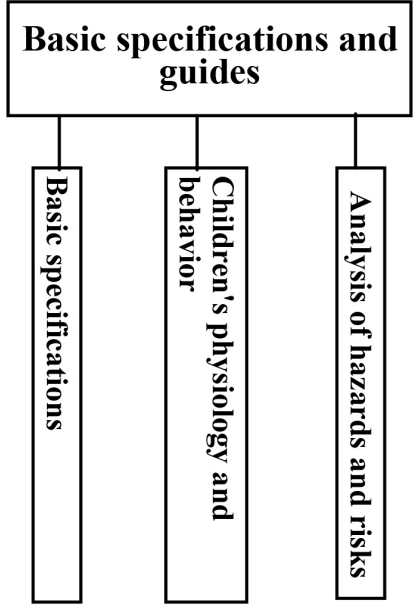

Figure 3. Technical body of "Basic specifications and guides". 


\subsubsection{Analysis of Hazards and Risks}

This part mainly carries out the work from the three aspects: product injury data analysis, risk monitoring and verification, and risk assessment, and based on the conclusion of risk assessment, puts forward some suggestions on establishing projects of standards related to high-risk products. In addition to serving this system, the national standards in this field are also applicable to the supervision by import and export ports and the risk supervision of infants and children's products in the domestic market.

\subsection{General Technical Requirements}

To solve the coordination and consistency problems of standards of other standardization committees related to infants and children's products, a sub-system of "General technical requirements" is set up for research(see Figure 4). From the perspective of standard integration and optimization, this system is more to provide an "entrance to specifications". For the existing standard products, technical requirements will be no longer set, but relevant standards are directly referred. For products not constrained by any standards and specifications, this part will comprehensively cover the use performance and safety performance of the products to promote and ensure that the new products meet the "minimum safety requirements".

\subsection{Specific Technical Requirements of Products}

This part mainly focuses on the development of specific technical requirements of relevant products within the standard formulating and revising scope of SWG 18 , which is the core part of this system. By referring to the relevant sub-technical committees including the European Union CEN/TC 252, the United States ASTM F15 and ISO/TC 310, and considering the demand degree of product marketing and standardization, injury risk and product recall at home and abroad, a research on the sub-systems has been done as below (see Figure 5).

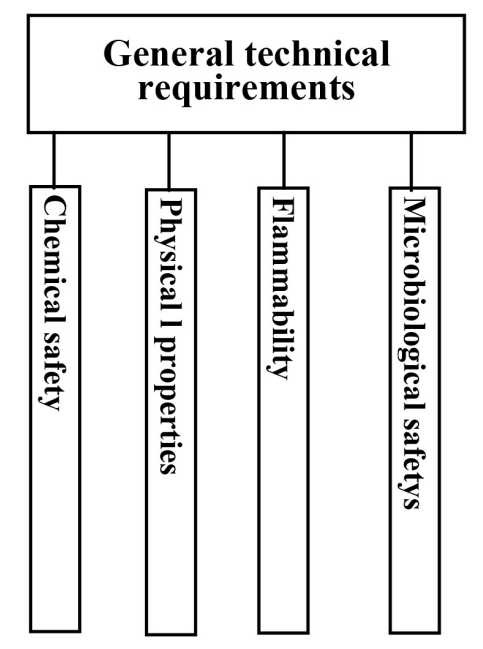

Figure 4. Technical body of "General technical requirements". 


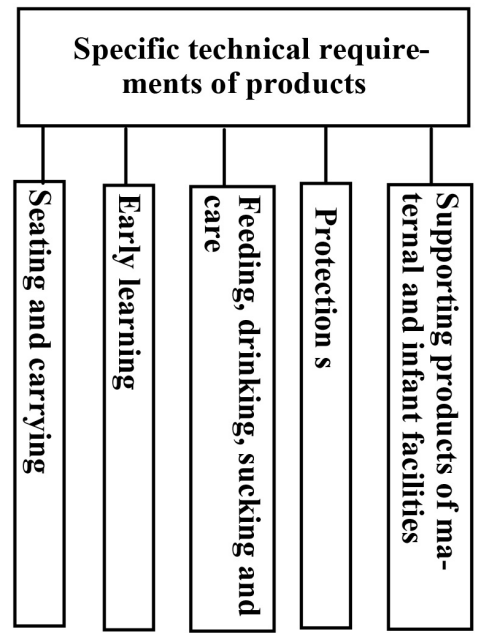

Figure 5. Technical body of "Specific technical requirements of products".

\subsubsection{Seating and Carrying}

This type of products is mainly used for infants and children (especially for those who can't sit or lie on their own) to ride and lie for a short time. The main product categories include carrying-type soothing appliances, bathing appliances and other products for supporting children's body. Among them, the carrying-type soothing appliances include infant recliners, bouncers, floor chairs and other non-sleeping bed products. At present, there are no relevant standards for this type of products, and most enterprises choose to develop enterprise standards. This type of products has great safety risks, for example, reclined infant rockers have its reclining angle of $10^{\circ}-30^{\circ}$ and even the maximum angle of over $40^{\circ}$. When a baby is supine on a rocker with such an angle, it is difficult for it to turn over. The baby's chin may be located against the respiratory tract, causing suffocation. According to EU and US statistics of defective products (European Commission, 2021; United States Consumer Product Safety Commission), this type of products has been confirmed to be related to 73 infant deaths from 2005 to June 2019. However, in the context that European and American countries take such products down from the shelves, due to the lack of relevant standards, it is difficult for China to put risk control in place and high-risk products are still in the market.

\subsubsection{Early Learning}

This type of products is mainly for training the sensory coordination of infants and children 6 years old and younger and for them to learn life skills and mainly used at homes, in educational institutions, nurseries/kindergartens, etc. Product types mainly include products for sensory integration training and products for chewing-aid training. With the upgrading of parenting concept in China, this type of products has gradually appeared. At present, no special standard system is available for this type of products in China yet and most of the products can only be standardized in accordance with GB 6675 series of toy standards. However, this type of products is mainly used for learning and training of specific 
purposes, so it is difficult to include them in or exclude from the scope of application of toy standards, resulting in that products superficially meet the national safety requirements, but their unique characteristics and safety risks have not been effectively reflected and fully constrained. Therefore, it is necessary to develop corresponding standards in this field.

\subsubsection{Feeding, Drinking, Sucking and Care}

This type of products mainly includes body care products, mouth cleaning \& care products and feeding \& sucking products, which all are daily necessities for infants and children. Among them, feeding and sucking products are mainly baby tableware, milk/water utensils, bibs, etc. This type of products on the market in China is generally in accordance with the General Safety Requirements for food Contact Materials and Articles (the national food safety standard), but those standards are not a product standard and there is a lack of mechanical and physical safety requirements, which might pose a serious safety risks of this type of products. According to information, most enterprises can only develop enterprise standards by combining the safety requirements for food contact materials with those for mechanical and physical properties. Not to mention whether or not the standards meet the requirements, this "helpless action" greatly increases the launching time and compliance costs of products. Therefore, it is very necessary to develop a complete set of feeding and sucking product standards.

\subsubsection{Protection}

This type of products is mainly used to protect infants and children from accidental injury and reduce the injury risk. According to the "Report on Child Injury Prevention" jointly released by the Chinese Center for Disease Control and Prevention and the Safe Kids Worldwide, injury is the first cause of death for children aged 0 - 14 in China and the high incidence age of accidental injury for children is concentrated before the age of 6 (Chinese Centre For Disease Control and Prevention, 2012). With the increase of the month age, infants move in a wider range, touch more surrounding things and subsequently develop their intelligence, physical fitness, language, thinking and communication ability rapidly. With a strong curiosity, infants like to try everything around them, but their muscle control, body coordination and emergency abilities are poor, so many facilities and activities in life are hazardous to infants. By use situation, this type of products is generally divided into protective equipment for use at home, daily sports and use in water.

\subsubsection{Maternal and Infant Facilities Supplies}

There is an increase in newborns with the comprehensive implementation of the two-child policy and the requirement of infant travel increases the demand for relevant supporting products of maternal and infant facilities. Consequently, more and more attention is paid to the construction and safety of maternal and infant rooms in various public places all over the country. In November 2016, 10 
ministries and commissions including the National Health Commission of People's Republic of China issued the "Guiding opinions on accelerating the construction of maternal and infant facilities", which puts forward the overall goal of "by the end of 2020, all public places and employers that should be equipped with maternal and infant facilities will have basically built standardized maternal and infant facilities", and takes "Standards go ahead" is one of the four basic requirements (National Health Commission of People's Republic of China, 2016). However, no safety technical standards or recognized research results are issued for relevant supporting products of maternal and infant facilities at home and abroad. In foreign countries, strict requirements have been made for the scale and basic equipment of maternal and infant rooms. The basic facilities include diaper changing table, breast-feeding seats and pools. It is urgent to develop and implement the relevant national standards of supporting products for maternal and infant rooms to resolve the problems above, ensure the safety of consumers in the use of maternal and infant rooms, improve and standardize the construction of maternal and infant rooms in public places.

\subsection{Test Methods}

The physiological characteristics of children are different from those of adults. Physiological data such as the size of each body part of children of all ages, the stretching range of possible movements, pulling force, pushing force, finger pressure, and tolerance to harmful chemical substances, are indicators for judging whether or not the products are hazardous to infants and the test method is the judgment method in turn. Different from general product test methods, the use habits, age and physiological characteristics of infants and children should be considered in developing the property test methods of juvenile products and there is a correlation between different types of infants and children product test methods (such as chemical test methods), so it is necessary to establish a complete system of test method standards. This sub-system includes chemical property tests, physical and mechanical property tests, burning behavior safety tests and microbiological safety tests, basically covering all property tests of juvenile products (see Figure 6).

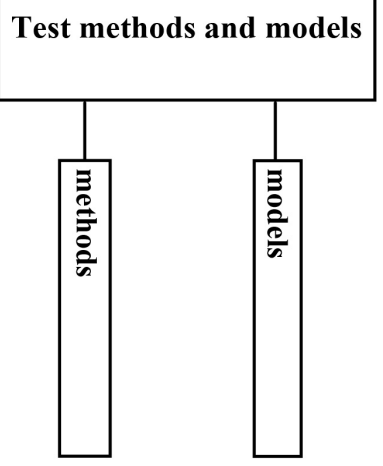

Figure 6. Technical body of "Test methods". 


\section{Conclusion}

The establishment of SWG 18 and the National Standardization System of juvenile products is conducive to the integration and optimization of existing standardization resources, leading the quality and industrial development of infants and children's products in China and effectively guaranteeing the health and safety of children. Next, SWG 18 will closely track the need for constructing standards for new business forms, focus on key links and key products, strengthen the forward-looking of standardization work and continue to improve the national standardization system of infants and children's products under the guidance of the national "14th Five-year(2021-2025) Plan".

\section{Acknowledgements}

The authors are grateful to the support of Research projects of General Administration of Customs of China (No.2020HK104).

\section{Conflicts of Interest}

The authors declare that they have no conflicts of interest.

\section{References}

China State Administration for Maket Regulation (2019). The Recalls of Automobiles and Consumer Goods in 2019. http://dpac.samr.gov.cn/xwdt/tpxw/202003/t20200331_90358.html

Chinese Centre For Disease Control and Prevention (2012). Report on Child Injury Prevention.

European Commission (2021). Rapid Alert System for Non-Food Consumer Products (Rapex).

https://ec.europa.eu/consumers/consumers_safety/safety_products/rapex/alerts/?event $=$ main.search\&lng=en

Jgm, V. E., et al. (2009). Chemicals in Toys: A General Methodology for Assessment of Chemical Safety of Toys with a Focus on Elements. Rijksinstituut Voor Volksgezondheid En Milieu Rivm.

Liang, M. (2020). The Report of China Toy and Juvenile Products Industry. China Toy \& Juvenile Products Association.

National Health Commission of People's Republic of China (2016). Guiding Opinions on Accelerating the Construction of Maternal and Infant Facilities.

Standardization Administration of China (2020). No. 7th Announcements of Standardization Administration of China.

Standardization Administration of China (2021). National Public Service Platform for Standards Information. http://std.samr.gov.cn

United States Consumer Product Safety Commission (CPSC) (2021). Consumer Product Recalls. https://www.cpsc.gov/Recalls 